\title{
Selectively Incapacitating Frequent Offenders: Costs and Benefits of Various Penal Scenarios
}

\author{
Arjan A. J. Blokland · Paul Nieuwbeerta
}

Published online: 31 July 2007

(C) Springer Science+Business Media, LLC 2007

\begin{abstract}
A small number of offenders are responsible for a disproportionate share of total crime. Policy makers have been seeking to reduce crime more efficiently by targeting corrections at these frequent offenders. Thus far, both macro- and micro-level research have yielded mixed results regarding the effects of these kinds of selective policies. The current study uses data from the Netherlands Criminal Career and Life-course Study to estimate the incapacitative effects of alternative selective prison policies. Using the rolling cohorts method, implementations of various penal scenarios differing in selection rate, sentence disparity and selective accuracy are simulated. Results show that it is hard for selective policies to yield a positive societal result: costs of imprisonment typically exceed benefits gained from crimes prevented.
\end{abstract}

Keywords Selective incapacitation - Frequent offenders · Rolling-cohorts · Cost-benefit analysis

\section{Introduction}

Imprisonment aims to reduce crimes in three ways (Blumstein et al. 1978): general deterrence, specific deterrence and incapaciation. This study deals with this last, incapacitative effect of imprisonment. In particular it focuses on the effects of selective incapacitation, that is, imprisonment policies specifically targeting some predefined group of offenders.

\footnotetext{
A. A. J. Blokland $(\square) \cdot$ P. Nieuwbeerta

Netherlands Institute for the Study of Crime and Law Enforcement (NSCR), P.O. Box 792, Leiden 2300 AT, The Netherlands

e-mail: ablokland@nscr.nl

P. Nieuwbeerta

Utrecht University, Utrecht, The Netherlands
} 
Selective incapacitation policies are increasingly being implemented, both in the U.S. and in Europe. The rationale behind these policies is straightforward: reducing crime at lower cost. The more skewed the distribution of offence frequency in the offender population, the more offenses can be prevented by selectively incapacitating those offenders that are at the high end of this distribution. If frequent offenders are also more serious and violent offenders, as both theory (e.g. Moffitt 1993, 2006) and empirical research suggests (Piquero 2000a, b; Tracy et al. 1990; Wolfgang et al. 1972), the benefits of removing these offenders from society may be even greater (Piper 1985). Selective incapacitation however is not uncontroversial. Ethical objections have been raised to the sanction disparity inherent to these selective policies (e.g. Moore 1986). Others have stressed the 'stochastic' selectiveness that is already built-in to the judicial system, predicting low yields of an additional focus on frequent offenders (Blumstein et al. 1993; Canela-Cacho et al. 1997). Finally, researchers have pointed to the rising prison costs (Donohue III and Siegelman 1998), wastage of prison capacity (Blumstein 2005), the costly care of the aging prison population (King and Mauer 2001; Shichor and Sechrest 1996; Walker 2001), possible problems in monitoring growing groups of inmates serving long-term sentences, and the growing number of appeals lodged by those offenders meeting the selective criteria that may result from selective policies (Austin and Irwin 2001; Cushman 1996; Flanagan et al. 1998; Patch 1998).

Research into the effects of incapacitation has either been at a macro-level, combining aggregate data on prison populations and crime rates, or at the micro-level using models combining information on individual offence rates, probability of conviction and sentence length. Aggregate research is faced with the problem of separating the effect of imprisonment on crime from the effect crime has on imprisonment. See Piquero and Blumstein (this issue) and Miles and Ludwig (this issue) for reviews. Additionally, this type of research can only address the combined deterrent and incapacitative effects of imprisonment. Micro-level research does focus solely on imprisonment's incapacatative effect, but finds that outcomes vary widely depending on the estimates of the various criminal career characteristics used. Also, thus far these latter studies pertain to adult offenders only. Finally, extant research has been primarily based on North-American data; different conclusions may follow from using data from countries that differ from the U.S. in crime rates, offender characteristics and penal culture.

Our aim in this study is to examine the effects of various selective incapacitation policies in the Netherlands. We do this by simulating the effects of various hypothetical selective scenarios, varying in both selection rate and disparity ratio using data from the Criminal Career and Life-course Study, a longitudinal study of a Dutch conviction cohort followed up to age 72 .

\section{Earlier Research on Incapacitation and Crime}

\section{Macro-level Studies}

Studies into the effects of imprisonment on crime have used one of two approaches: macroand micro-level studies. Macro-level or, as Spelman (2000a) refers to them, top-down studies have relied on aggregate data on society-level crime rates and prison populations. These studies typically estimate the relation between crime rates and prison populations, whilst controlling for other variables that may affect crimes rates like the population's age distribution or its unemployment rate using multivariate regression techniques. In doing so, 
macro-level studies are unable to separate incapacitation effects from deterrence effects. Depending on the level of aggregation, these studies have yielded effects ranging from zero to a $2.2 \%$ decrease in crime resulting from a $1 \%$ increase in the incarceration rate (see: Spelman 2000b; Stemen 2007 for reviews). Nation-level studies have produced the largest effect sizes, but have trouble with dealing with the biasing effects of long-term social trends (Spelman 2000a). U.S. state-level studies have found more modest - and arguably more realistic - effect sizes $(-0.06$ to -0.40$)$. Yet, many of these studies did not control for simultaneity, that is, the fact that while prison rates may affect crime rates, crime rates in reverse may affect prison rates. If the increase in prison population is caused by an increase in crime rates, this will downplay the results of imprisonment and may-when worst comes to worst-even make it look like increasing imprisonment increases crime rates. Today only three studies have accounted for simultaneity. Both Levitt (1996) and Spelman (2000a) made comparisons between 50 U.S. states, Spelman (2005) compared Texas counties. These latter studies yield elasticity estimates from -0.26 to -0.44 , with somewhat larger effects for violent compared to property crimes. Due to their design, the effects from these macro-level models typically pertain to the combined deterrent and incapacitative effects of imprisonment.

Instead of analyzing long-term trends, other researchers using aggregate data have specifically focused on the implementation of selective policies, most often the 'three strikes' laws (Clark et al. 1997; Vitiello 1997; Zimring et al. 2001). As with the studies on imprisonment in general cited above, many of the studies into selective imprisonment did not control for simultaneity. This may lead effects of these selective policies to be underestimated, since outcome measures may also be affected by pre-existing increasing crime trends that gave rise to implementing the selective policy in the first place. Many studies also have a short follow-up period. However, as Kovandzic (2001) notes, the incapacitative effects of selective policies most probably do not occur for many years after the policy is implemented, since most offenders selectively imprisoned under the new policy, would have been imprisoned for at least some period even under prevailing nonselective policy. Using long-term data from Florida, Kovandzic (2001) finds little evidence for a general deterrent effect of Florida's habitual offender laws on crime, and concludes that its limited effects on crime are mostly due to incapacitation.

It must be noted however, that while policy shifts on imprisonment in the U.S. have been both quick and dramatic, these data are far from experimental (Spelman 2000a). Decisions to expand imprisonment or to implement a selective policy did not occur randomly, and therefore results of these changing conditions are confounded with existing between-state differences in crime trends and prison rates and all other factors that may have influenced either one of these variables. Results, even of the most complex models, are therefore still potentially subject to bias.

\section{Micro-level Studies}

Instead of relying on aggregate data, micro-level, or bottom-up studies try to model the workings of the criminal justice system in more detail. Making estimates of the offense rate per year, the probability of arrest and conviction, and the average sentence length, these studies calculate the proportion of his/her criminal career the typical offender will spend imprisoned (Avi-Itzhak and Shinnar 1973; Cohen 1978, Greenwood and Abrahamse 1982). This proportion then represents the benefits of imprisonment in terms of decreased crime rates. Unlike most aggregate studies, these micro-level studies focus solely on the 
incapacitative effect of imprisonment. Recent studies by DiIulio and Piehl (1991), Spelman (1994) and Piehl and DiIulio (1995) have yielded elasticity estimates ranging from -0.16 to -0.26 . However, recognizing the still limited precision of the estimates used, Spelman (2005) concludes that it is more reasonable to expect a $0.1-0.3 \%$ decrease in crime for a $1 \%$ prison expansion. Micro-level studies necessarily make assumptions about several criminal career characteristics. Small—and plausible — changes have been demonstrated to considerably affect the studies' outcomes (Spelman 1994). While over the years these studies have gained validity, as a result of more detailed data on criminal career becoming available, they still need to rely on simplifications regarding the distribution and interrelationships of the various criminal career dimensions (Spelman 1994: 110).

In an effort to circumvent uncertainties and simplifications tied to the use of criminal career estimates, Bernard and Ritti (1991) designed a rolling cohort methodology that allowed them to estimate the incapacitative effect of selective policies using actually observed data. Their analyses were based on count data from the Philadelphia birth cohort. In brief, they simulated the implementation of some hypothetical selective policy and then counted the actual number and type of offences recorded after the youth had been incapacitated under the hypothetical policy. These offenses would make up the incapacitative effect of the selective policy since they would not have occurred under the selective policy, but actually did occur under existing, non-selective policy. Based on only the 'chronic' offenders in the Philadelphia cohort (those offenders who accumulated at least five police reports) a selective policy which entailed imprisoning a youth after his second arrest until his 18th birthday resulted in a 25\% decrease in all reported crimes and a $35 \%$ decrease in the serious crimes reported for this cohort. A similar study using Swedish birth cohort data showed that imprisoning every recidivist in this cohort for a period of 2 years would reduce registered crime for this cohort by 28\% (Andersson 1993). However, while both studies found that selective incapacitation would reduce crime, both studies also showed implementation of a selective policy would markedly inflate prison populations by as much as 22 times the rate under non-selective policy.

\section{Aims of This Study}

As just shown, extant research on selective incapacitation has been problematic. Given the observational nature of the macro-level data used researchers experience difficulties in eliminating the biases caused by possible confounding factors. Micro-level studies on the other hand rely on estimations of several criminal career dimensions and necessarily need to make simplifications regarding the interrelationships between these dimensions. Therefore, estimates of the effect of selective incapacitation on crime vary widely, not in the least part due to problems of model specification.

In addition, the far majority of studies on the incapacitative effect of selective policies have been on U.S. data. The extent therefore to which any of these studies results would apply to countries other than the U.S. is far from clear. This overreliance on U.S. data is especially unfortunate, since there are many reasons why the effects of (selective) incapacitation would be different in the U.S. compared to other-for example European countries. For one, both serious violent crime rates and imprisonment rates in the U.S. are higher in European countries. Furthermore, a relatively harsh penal climate in the U.S., drives up the period of selective imprisonment needed in order to effectively achieve disparity. 
The aim of this paper is to estimate the costs and benefits associated with various forms of selective detention policy in the Netherlands. The Netherlands has been characterized by relatively low violent crime rates, and a lenient penal climate — at least up to 1990_resulting in the imprisonment rate being low, comparatively few convicted offenders being sentenced to prison, and mostly short prison sentences being imposed (Kommer 1994; Smit 2001). Examining the effects of selective incapacitation in a Dutch context is of special interest since the Netherlands recently began implementing selective incapacitation policies. Finally, Dutch researchers have not previously addressed this topic and the extent to which these newly implemented selective policies might affect crime are therefore as yet unknown.

In the current study we will address the following questions:

(1) What is the predicted decline in registered crime following the introduction of a selective incapacitation policy, and is this decline similar across offense types?

(2) What is the predicted increase in the prison population associated with selective incapacitation policy?

(3) On balance, what are the benefits and costs of a selective incapacitation policy?

(4) How accurate-in terms of prison wastage-are selective policies?

\section{Estimating the Effects of (Selective) Incapacitation}

The golden standard for estimating the effects of any policy would be a true randomized experiment which would involve comparing crime rates of two societies that were-and remained-completely similar besides the implementation of some clearly defined policy. The conditions requisite for a controlled experiment however are very unlikely to arise, and, even when they do arise, experiments on selective incapacitation-especially when sentence disparity is high-would meet with serious ethical concerns. It is therefore that researchers have turned to so called simulation studies that come closest to the experimental ideal. The danger of simulation studies is that in order for the simulation to work, researchers must make many-and often unclear-assumptions, incurring the outcomes at risk of becoming unrealistic.

The simulation methodology designed by Bernard and Ritti (1991) — in our viewcomes close to a true experiment and its underlying assumptions are easily grasped. Their rolling cohort method compares the actual observed number of offences for some offender population under prevailing policy with those that would have been prevented under a hypothetical selective policy in that same population. As a result pre-treatment conditions in the experimental group and the control group are exactly similar, since they are in fact the same population. Assuming a 'steady state' of rolling cohorts further prevents the outcome variable to be biased due to effects of long-term social trends or temporal fluctuations unrelated to the experimental treatment. In addition, as a result of this 'steady state' any change in the outcome variable is entirely due to incapacitation. Since the rolling of the cohorts can-in principle-go on indefinitely, this method is also well suited for examining the long-term effects of selective incapacitation policies. Finally, the outcome variable can be distinguished in terms of benefits-the number of actually observed offenses that would not have occurred under selective policy - and costs - the incarceration rate that would result from selective policy, relative to the incarceration rate under non-selective policy. This allows for making isolated and unbiased inferences about the incapacitative effects of the (hypothetical) selective policies proposed. It is therefore that we adopt this method in this study. To do so, we use data from the CCLS. 


\section{Data and Methods}

\section{Criminal Career and Life course Study (CCLS)}

This study uses data from the Criminal Career and Life Course Study (CCLS) which is being carried out at the Netherlands Institute for the Study of Crime and Law Enforcement (NSCR). The CCLS is a large-scale longitudinal study charting the complete criminal careers of a large number of individuals (Nieuwbeerta and Blokland 2003). The CCLS is based on a sample of $4 \%$ of all criminal cases in which a final ruling was pronounced by a Dutch court or a public prosecutor in 1977 (Block and Van der Werff 1991). The CCLS covers the entire subsequent period up to 2003 and thus contains unique prospective data for a period of 25 years. The analyses made for this paper are based on the data of the criminal careers of 4,615 individuals (Blokland, Nagin and Nieuwbeerta 2005; Blokland and Nieuwbeerta 2005). ${ }^{1}$

In charting the criminal behavior of the individuals in the sample, the CCLS works with extracts from the Criminal Records Register. These extracts record all the criminal cases registered by the police with the Public Prosecutions Service, identify which court decided on the case, what the decision was, whether any sentence was pronounced and if so, what that sentence was. The CCLS - data thus pertain to cleared crime only: offenses for which the offender was never apprehended are not considered. In order to answer the present research questions, we have chosen to include only registrations from the extracts in relation to a criminal offense mentioned in the Dutch Criminal Code (including the Opium Act and the Weapons and Ammunition Act but excluding acts such as the Economic Offenses Act and the Road Traffic Act) and that resulted in a conviction or a discretionary dismissal. Cases that ended in an acquittal or in a dismissal because judged too weak for conviction therefore did not count in determining a person's criminal career, nor did registrations of petty offenses (misdemeanors).

\section{The Rolling Cohort Simulation Method}

To estimate the consequences of the various selective policies we use the so-called 'rolling cohorts' method, as introduced in the selective incapacitation literature by Bernard and Ritti (1991). Conceptually this method closely follows the logic of a true controlled experiment. Let us consider the important features of the method as we apply it in this paper:

1. The rolling cohort method creates two hypothetical societies.

2. At a certain point in time (here 1977 given the nature of the data of the CCLS) a new selective incapacitation policy is implemented in one of the societies. This is our experimental society.

3. No new policy is implemented in the other. This is our control society.

\footnotetext{
1 To allow us to make statements about more serious offenses that occur less frequently, a number of types of offenses were oversampled. Traffic offenses were such a frequent occurrence in 1977 that a sample of $2 \%$ was deemed to be enough for this type of offense. Moreover, the structure of the sample was a $4 \%$ sample of all cases, not persons. As a result, individuals who were registered for more than one case in 1977 had a higher chance of being included in the sample than individuals who were only involved in one criminal case that year. For these reasons, a weighting factor has been used for this paper so that the distribution of both cases and persons in the sample is representative for the distribution in 1977. For more precise information on the CCLS please refer to (Blokland 2005; Nieuwbeerta and Blokland 2003).
} 
4. The experimental society and the control society are identical (a) at the start of the experiment, (b) during the experiment, and (c) after the experiment - on all aspects except the implementation of the selective policy, thereby fully controlling for simultaneity. In our case this means that-except for the implementation of the selective incapacitation policy, both societies are and remain identical-e.g. with respect to the characteristics of both offenders and their criminal careers and the probability of conviction given an offence-to the Dutch situation in $1977 .^{2}$

5. The treatment in the experimental society is clearly defined-and manipulated by changing the sentence disparity of the (hypothetical) selective policy. Here: 2, 5, 10 or 20 years of imprisonment.

6. The inclusion criteria are clearly defined rendering all offenders that show predescribed criminal history features-e.g. minimum number of convictions-liable for selective treatment. The literature shows no consensus with regard to which offenders should be regarded as frequent offenders; every study using its own working definitions. In the American three-strikes legislation, the limit for frequent offenders for example is three (and in the case of California sometimes even two) convictions for a criminal offense. Bernard and Ritti (1991) as well as Andersson (1993) based their calculations of selective policy effects on a classification with a limit of two convictions (or arrests or institutionalizations in case of Bernard and Ritti). The international criminological literature generally uses five contacts with police or judicial authorities to define the frequent offender (Barnett and Lofaso 1985; Blumstein et al. 1988; Kempf-Leonard et al. 2001). Since our study pertains to Dutch data, and we want to stay close to the policy measures recently introduced in the Netherlands, we use 3,5 or 10 prior convictions for selection into the selective treatment and standard prison terms of 2, 5, 10, 20 years. (Grapendaal and Tilburg 2002; Versteegh et al. 2003). This gives an adequate insight into the marginal costs and marginal benefits of various penal scenarios under which special groups of offenders are selectively incapacitated in the Netherlands.

7. The outcome measure is clearly defined. It consists of all convictions that are actually observed-but would have been prevented in the experimental society. In that sense the benefits calculated are marginal. By defining the benefits as reduction in conviction, not in actual crimes committed, the model does not disregard the complex dynamics underlying the evolution from actual to cleared crime, but merely assumes these dynamics to be similar across cohorts.

8. The effects of the treatment are appropriately isolated in that the outcome measure only represents the incapacatative effects of the selective policy. The simulation thus does not allow for any behavioral or system effects that may follow implementation of a selective incapacitation regime. To the degree selective policies attain greater general and specific deterrence, a focus on just the incapacatative effects of selective policy underestimates the benefits of these selective policies (Shepherd 2002). However, to the extent implementation of a selective policy leads to a 'hardening' of crime-offenders facing long-term incapacitation going to extremes to avoid detection, even if for example this would mean they would have to kill for it (Kovandzic et al. 2002; Marvell and Moody 2001; Shafer 1999)_a focus on incapacitation may in turn overestimate selective policies ultimate benefits. The model further assumes that others—who would not otherwise have offended—do not replace

\footnotetext{
${ }^{2}$ Making use of the offender's criminal history estimating the effects selective policy assumes this stability to entail the period prior to the sampling year as well.
} 
the incarcerated offenders. Nor does it account for the possibility that offences committed in groups would still have taken place even if one group member was absent due to him or her being selectively incapacitated (Donohue III and Siegelman 1998; Mathiesen 1998; Zimring and Hawkins 1995), ${ }^{3}$ leading to further overestimation of the policies final effects.

\section{The Rolling Cohorts Method}

Technically rolling cohorts can be implemented by creating a number of additional cohorts $_{t+k}$ where $k=1$ through 50 by simply adding $k$ to each year of each offender's criminal history as captured in the original data-set as observed in the sampling year. For example: an offender in the original 1977-cohort whose criminal history showed two convictionsone in 1975 and one in 1977-will be mirrored by an offender in cohort $t_{t+1}$, whose convictions occurred in $1976(1975+1)$ and $1978(1977+1)$. That same offender will be represented in cohort $t_{t+2}$ by an offender who was convicted in $1977(1975+2)$ and 1979 $(1977+2)$ and so on. In this way we used data on the original cohort $t$ to create additional cohorts up to $t+50$. Under prevailing policy the assumption of rolling cohorts will lead to a steady crime rate across $k$ years equal to the level of crime in the sampling year. In analyzing the benefits of selective policy this rate will serve as the base rate.

To estimate the effect of selective incapacitation on crime we then introduce selective policy to each cohort as of 1977, say a selective policy under which each third offense automatically leads to 2 years of imprisonment. Introducing the selective policy has the effect of altering the number of offenders convicted in the years $k=1-50$. To understand why this is so, imagine an offender in the original cohort that had four prior convictions in 1977: two in 1975, one in 1976 and one in 1977. This offender will be mirrored by an offender in cohort $t_{t+1}$ who is convicted twice in 1976, once in 1977 and once in 1978. However, if the above mentioned selective policy was introduced in 1977, this particular offender would not have been free to offend in year ${ }_{t+1}$. Due to accumulating his third conviction in 1977, this offender would have been selectively incapacitated for 2 years and therefore unable to commit the crime or be convicted in the year ${ }_{t+1}$. To estimate the benefits of selectively incapacitating frequent offenders we can compare the number of convictions in each year under the steady rate of rolling cohorts resulting from prevailing policy with the number of convictions in years $t+k_{1-50}$ for the additional cohorts $t+k_{1-50}$ under selective policy. ${ }^{4}$ Given that the selective policy allows offenders to start of with a clean slate, those offenders with long enough criminal histories-criminal histories that extend beyond the period of selective incapacitation-may re-appear in later cohorts. Eventually selective policy will result in a steady crime rate, but one that is below that of non-selective policy.

To estimate the costs of selectively incapacitating frequent offenders, that is, to estimate the growth in the prison population we can compare prison population rates in a similar vein. Prevailing policy would lead to a steady prison population across years $t+k_{1-50}$. Selective incapacitation on the other hand will lead to an increase in the prison population because every subsequent cohort new offenders will be selectively incapacitated, while

\footnotetext{
3 More technically: the model is based on person/incident combinations and not on incidents.

4 Note that we examine the effects of selective policy over and above non-selective policy, that is, offenders not liable for selective imprisonment are assumed to be sentenced as they would have been under prevailing non-selective policy.
} 
some selectively incapacitated in previous years will not yet have been released. This growth in prison population is partly counteracted by the decreasing numbers of offenders in each subsequent cohort free to commit crime especially in the years directly following year $t$.

Finally, given the long-term prospective nature of the data used, we can also estimate the wastage of prison capacity of the selective policies elaborated here. This is established by simply counting the number of convictions after year $t$ observed under prevailing nonselective policy for those years a given offender would have been imprisoned if he would have been subjected to a given selective incapacitation regime. Years beyond the last conviction during which an offender would be selectively imprisoned are defined as wasted. This approach differs from that described above in the sense that here we use prospective data, while we use retrospective data to estimate both the decrease in registered crime and the increase in the prison population. ${ }^{5}$

\section{Results}

\section{Benefits: Decrease in Crime}

First we focus on the possible benefits of selective policies: what will be the decline in crime following the introduction of a selective incapacitation policy? For this we compare the number of convictions after the introduction of a selective approach with the number of convictions under prevailing policy. Working with rolling cohorts, the number of convictions under prevailing non-selective policy would remain the same as in 1977. For our sample, this boils down to an absolute number of 3,092 criminal convictions for each subsequent year-under a 'steady state'-for our sample of 4,615 offenders, and 101,980 in the society given a population of 16 million inhabitants (thus assuming there is no population growth). This is shown in Fig. 1 by means of the $0 \%$ line. Figure 1 further shows the expected decrease in convictions under the various forms of selective policy compared to the level under non-selective policy. Selectively incapacitating offenders who have a fixed number of convictions to their name leads to a decrease in convictions in all cases. With selective incapacitation, the number of convictions decreases because an increasing percentage of offenders is imprisoned for a longer period. The big drop immediately after introducing the selective policy is caused by offenders who already had more than the fixed number of convictions to their name in 1977. This is because, assuming that the policy is introduced in 1977 (year 0), crimes committed before 1977 count as well.

Surely, convictions only represent a fraction of all crimes committed. Comparing conviction rates to registered crime rates and estimates based on victim-surveys yields some insight in the way the number of convictions relates to number of actual crimes. For example: in the Netherlands in 2004, the ratio of convictions is about 1 to every 16 crimes registered by the police, and 1 to every 46 crimes reported in victim-surveys (Wittebrood 2006). Convicted offenders may very well be responsible for a considerable part of the total number of reported victimizations. Yet, if we-for the moment-assume that regardless of the type of offense every offender has the same risk of being registered and convicted, the $(\%)$ drop in conviction rates also represents the attended drop in actual crimes committed.

\footnotetext{
5 A more elaborate account of the rolling cohort method can be obtained at http://www.nscr.nl/medewerkers/pub/ablokland_pubE.php
} 
Fig. 1 Estimated decrease in registered crime under various forms of selective policy (in \%)

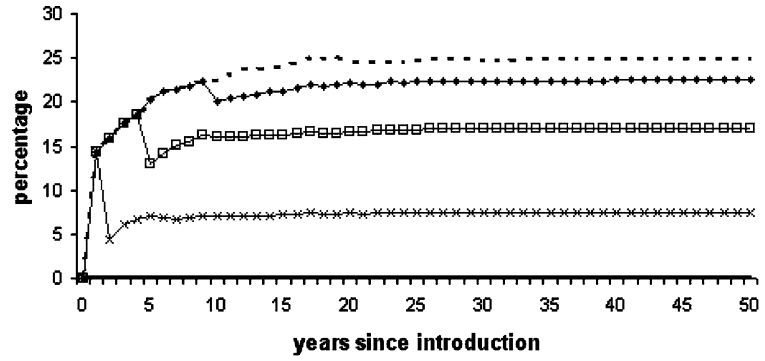

$\longrightarrow$ non-selective policy $\longrightarrow-3$ conv. 2 years $\quad \square-3$ conv. 5 years
-3 conv. 10 years $\quad---3$ conv. 20 years

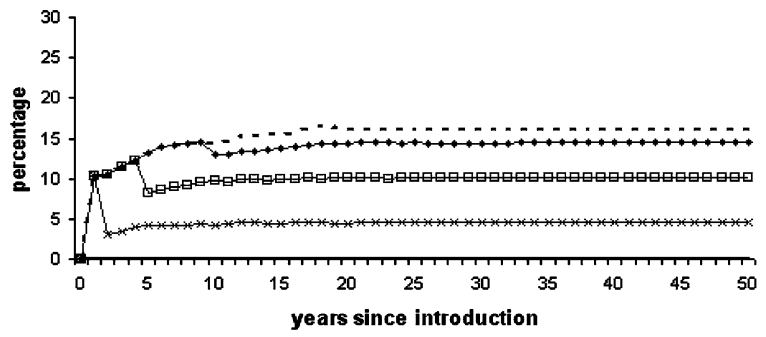

$\longrightarrow$ non-selective policy $\longrightarrow-5$ conv. 2 years $\longrightarrow \square-5$ conv. 5 years
$\longrightarrow 5$ conv. 10 years $\quad---5$ conv. 20 years

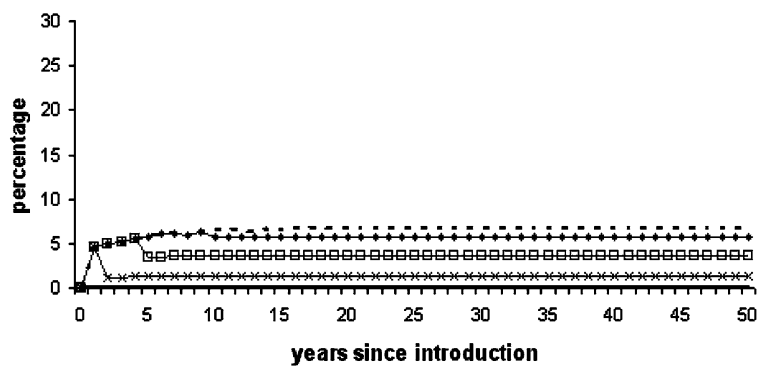

$\longrightarrow$ non-selective policy $\longrightarrow-10$ conv. 2 years $\longrightarrow-10$ comv. 5 years
$\longrightarrow 10$ conv. 10 years $--=-10$ conv. 20 years

Figure 1 also shows that when the number of years after the introduction of the selective policy is equal to the number of years of selective detention, the number of convictions rises again. This is because, after a period of selective incapacitation, offenders are released and some of them acquire additional convictions. Ultimately the number of convictions stabilizes. Figure 1, for example, shows that a selective policy imprisoning offenders for 2 years after their third conviction ultimately leads to a decrease in the convictions of $7.5 \%$. The analyses clearly show that the longer the period of detention, the larger the decrease in convictions. However, each additional year of incapacitation makes a smaller contribution to the decrease in convictions. For instance, doubling the period of imprisonment from 10 years to 20 years only yields an additional reduction in convictions of $3 \%$. 
The analyses further show that, a selective scenario with a high selection rate (a selective scenario applying a broad definition of 'frequent' offenders) results in the largest decline in convictions. If the selection criterion is five or ten offenses, registered crime ultimately shows less decline than if the criterion is three convictions. This is because fewer offenders meet these stricter criteria.

The yields of a selective policy are not only determined by the number of offenses but also by the nature of these offenses. More detailed analyses-not presented here-show that the decrease in convictions is not limited to one particular type of offense, but occurs more or less equally across the board. Under most of the scenarios, the decrease in convictions for drug-related offenses is the largest. From this it may be concluded that drug-related offenses are committed by offenders who have a long criminal history. The projected decrease in the number of convictions for violent offenses is small. This indicates that frequent offenders are not more likely to be convicted for violent offenses.

\section{Costs: Growth in Prison Population}

Selective incapacitation of frequent offenders can thus cause the number of convictions and hence crimes to decrease. But at what cost in terms of increased prison expenditures? We show the estimated increase in the population of prison inmates under the various selective scenarios in Fig. 2. To a certain extent, this development mirrors the changes in convictions shown in Fig. 1. Here the number of offenders imprisoned each year under non-selective policy forms the basis for the comparison. If the non-selective policy were to be continued, then each year 142 offenders from our sample, and 6,833 in a society of 16 million inhabitants would be imprisoned. ${ }^{6}$ This figure serves as the zero line in Fig. 2.

The other lines in this figure show developments in the number of additional prisoners under the various forms of selective incapacitation policy introduced in the year 0 . The rapid rise in the number of prisoners in the first years following the introduction of selective policy results from the number of offenders who already had more than the fixed number of convictions to their name in the year of introduction. In the first years after introduction of the selective policy, the number of prisoners continues to rise steadily because each year new cohorts are imprisoned before any earlier cohorts are released. The peak in the number of prisoners always occurs in the year in which the number of years after the introduction of the selective policy is equal to the number of years of selective detention. Only when the number of years after introduction is larger than the period of selective detention does the prison population decline and eventually stabilize.

Figure 2 shows that even a relatively mild selective policy results in a considerable increase in the number of prisoners. If the standard prison term is 2 years after three convictions, it ultimately results in a prison population more than 6.5 times $(650 \%)$ larger than under non-selective policy. A standard prison term of 5 years causes the number of prisoners to rise by a factor of 13 , while the strictest selective policy leads to a prison population that is 45 times as big as under prevailing policy.

\footnotetext{
${ }^{6}$ In fact this refers to man-years. Many prison terms imposed under prevailing policy are shorter than 1 year. In these cases the terms have been aggregated: two offenders each sentenced to 6 months in prison count as a single man-year. Imprisonment is always stated in whole years and 1 year always stands for one person. For the total offender population in 1977 , this would mean 6,833 man-years.
} 
Fig. 2 Estimated growth of the prison population under various forms of selective policy (in \%)
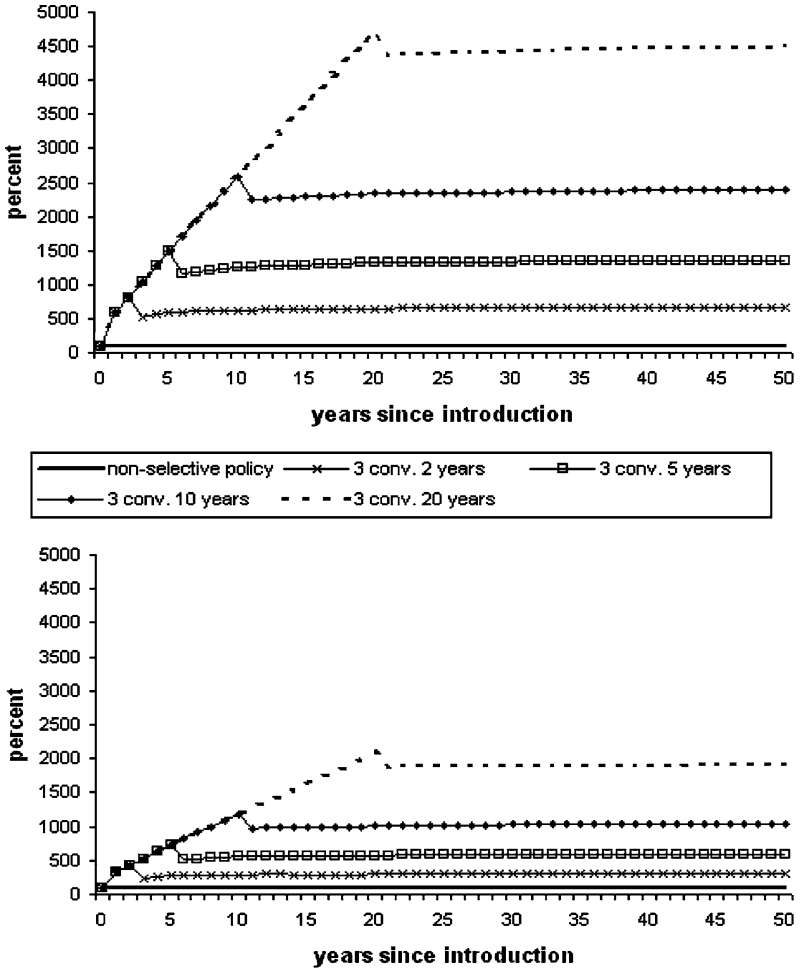

$\longrightarrow$ non-selective policy $\longrightarrow-5$ conv. 2 years $\longrightarrow \square-5$ conv. 5 years
$\longrightarrow 5$ conv. 10 years $\quad--5$ conv. 20 years

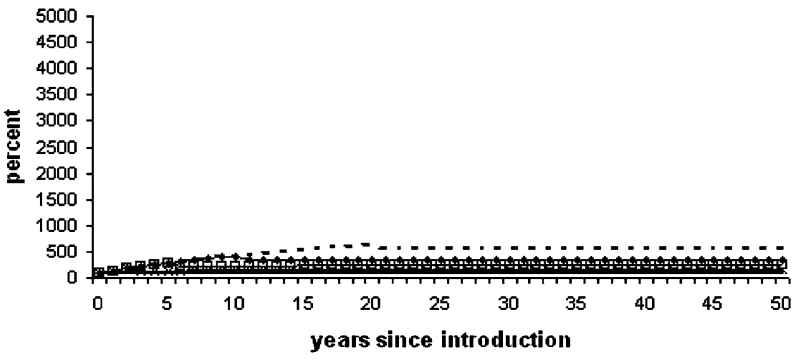

$\longrightarrow$ non-selective policy $\longrightarrow * 10$ cony. 2 years $\longrightarrow-10$ conv. 5 years
$\longrightarrow-10$ cony. 10 years ---10 cony. 20 years

If the criterion for selective detention is raised to five or ten convictions, then the prison population increases less because each year fewer offenders meet the selection criterion. Even so, a policy based on five previous convictions still results in an increase of between 3 and 19 times the non-selective population, depending on how long detention lasts. A criterion of ten previous convictions results in a population of one and a half to six times the non-selective population. It will be clear that, no matter what selective approach is taken, selective detention of frequent offenders entails high costs. 


\section{A Comparison of Costs and Benefits of Selective Detention Policy}

What about the cost/benefit ratio of a selective incapacitation policy? In other words, how efficient is such policy? This requires estimation of all costs and benefits, of say a prison term or other punitive measure, and these costs and benefits must then valued in comparable units, such as money. The latter presents problems in relation to criminal policy because of the lack of consensus about how to value the benefits of crime reductions and, to a lesser extent, the costs of prison expansion (Cohen 2005). For instance, the costs of property offenses are sometimes based on the value of the stolen goods, and the costs of violent offenses often include the medical costs directly arising from the event, with a possible loss of income as the lower limit. Other measures include damages awarded by juries (in the U.S.) and benefits paid by the victim support fund for violent offenses (in the Netherlands) giving some degree of weight to mental and emotional damage (Cohen and Miller 2003; Miller et al. 1993; Molenaar 2005; Rajkumar and French 1997; Gibbons 2004). Related costs such as the loss of gainful employment or the payment of a benefit to surviving family members must be taken into consideration here. ${ }^{7}$ The costs of a growing prison population must also be included in the calculations: new prisons will need to be built and maintained, growing numbers of prisoners have to be provided for, and new staff needs to be hired and trained. No precise figures are known for many of these costs.

\section{Costs and Benefits in Relative Terms}

However, without having to estimate the absolute value of a prevented conviction or the costs of a year of imprisonment, we can set up a framework within which we can weigh the advantages and disadvantages of any selective policy. We do this by calculating the result for society on the basis of a relative measure: the cost/benefit ratio. The cost/benefit ratio is a simple indication of the possible relationship between the value attributed to the yield (in terms of convictions prevented each year) of a selective policy and the social costs (in terms of the costs per prisoner per year). The result for society (RS) of a selective policy can be calculated as follows:

$$
\mathrm{RS}=(\mathrm{PC} \times \mathrm{BPC})-(\mathrm{PD} \times \mathrm{CYD})
$$

where PC stands for the number of prevented convictions and BPC for the benefits per prevented conviction. PD stands for the number of persons in detention and CYD for the costs of a year of detention. The cost/benefit ratio (CBR) than can be stated as: ${ }^{8}$

$$
\mathrm{CBR}=\mathrm{BPC} / \mathrm{CYD}
$$

\footnotetext{
7 The detention of false positives also entails costs that are difficult to express in monetary terms.

${ }^{8}$ Implementing the results shown in Figs. 1 and 2 in this equation reveals that for a policy meriting selective incarceration of either two or 5 years at the third conviction to be beneficial to society, then for each prevented conviction more than four times the costs of 1 year of detention must be saved; for longer standard detention periods, this figure mounts up to more than eight times. Similar calculations show that even when selection takes place after five or ten convictions, the benefits of a prevented offense must still be three to five times higher than the costs of 1 year of detention to prevent a social loss. More on the cost/benefit ratio in relative terms can be obtained at http://www.nscr.nl/medewerkers/pub/ablokland_pubE.php
} 


\section{Costs and Benefits in Absolute Terms: Euros}

We also translated the crime reduction benefits (BPC) and the incarceration costs (CYD) in euros. For this purpose we made use of calculations made by Dutch Ministry of Justice in the bi-annual publication on criminality and law enforcement from 2005 of Statistics Netherlands and the Research and Documentation Center (WODC) (Molenaar 2005). Total government expenditures on the fight against crime and on criminal law enforcement in 2004 were derived from the final budget act and accompanying explanatory notes, the autumn budget memorandum, the spring budget memorandum or the ministerial budgets, when possible supplemented with data from annual reports of related bodies. The calculated costs of crime also include the financial damage caused by crime to citizens, businesses and to the government based on surveys among the population and among businesses.

These calculations must still be viewed with a good deal of reserve: much of the damage sustained as a result of crime is difficult to express in monetary terms (e.g. emotional harm or injury, being incapacitated for work, and so on). Moreover, only indicative figures were available for many aspects. Further, many judicial bodies are not exclusively concerned with crime and fighting crime, which made it difficult to calculate the costs of these separate tasks. For example, based on estimates of the time spent on investigation activities in contrast to prevention and safety activities only one third of the total police budget was included. The calculated costs as well as the analyses we carried out with them must therefore be interpreted with caution.

In calculating the benefits of selective policies, we need to make the step from actual crime costs to convictions as observed for our sample. We accomplish this by dividing the total yearly costs of crime in 2004 as calculated by the Dutch Ministry of Justice ( 15.5 billion euro) by the total number of convictions in that year $(101,980){ }^{9}$ This provides us with a 'price tag' (107,211 euros) for each conviction that represents the benefits gained by that conviction in terms of costs prevented. By taking the total costs of crime as a vantage point, we take account of that behind every conviction, there is an unknown number of unregistered offences, which will also be prevented by selectively incapacitating a given offender-under the assumption that the number of (un)registered offences prevented by means of selective incapacitation is the same for every prevented conviction (and convicted person). We further simplify by assuming that the cost per crime does not change with the total crime rate. ${ }^{10}$

Benefits thus refer to costs that are not incurred thanks to selective detention policy. The costs of selective policies are prison costs. The costs of imprisoning an offender in the Netherlands for 1 day are $€ 190$. Again we used the Ministry's price tag (=cost price) of a place in the prison system in $2004 .{ }^{11}$ Based on these price tags, we can calculate the costs

\footnotetext{
9 The total costs of crime include 12,617 billion euros because certain losses are prevented (in billion euros): material loss $(€ 4,019)$, fraud $(€ 7,100)$, physical and emotional damages $(€ 445)$, medical costs $(€ 151)$ and lost income (€902)). In addition, the 2,869 billion. euros are costs in reaction to crime: investigation and public safety (€1733), prosecution (€411), criminal procedure $(€ 213)$, enforcement of the verdict (without detention) (€273), support to suspects $(€ 215)$ and victim support (exclusive of benefit payments $€ 24$, see Molenaar 2005) for additional information). For our analyses prison costs under prevailing policy are excluded.

10 This may even slightly overestimate the benefits per prevented crime since some of the expenditures on crime will be less sensitive to decreasing crime levels-e.g. a 1\% drop in crime probably will not result in the Dutch government reducing the police budget by $1 \%$.

11 To arrive at conservative estimates we take the cheapest form of imprisonment. For example: the cost price in judicial youth detention centers hovers around 400 euros per person per day.
} 
and benefits of the various policy scenarios. We have calculated the costs-for the entire country of the Netherlands-in a year when the consequences of the policy scenarios have stabilized (see Figs. 1 and 2).

The results-given in Table 1 in billions of euros-show that the benefits from the selective scenarios we calculated range from 0.2 to 2.7 billion euros. A high selection rate (a lenient definition of frequent offenders) and a high disparity ratio (a long period of increased detention) both contribute to the benefits of selective policy. The greatest benefit can be expected from a policy that combines the two.

The costs of a selective policy are also determined by the selection rate and disparity ratio. The costs we have calculated for the various selective scenarios range from 0.5 billion to 14.4 billion euros and our calculations show that selective policy with a high selection rate combined with a high disparity ratio yields the highest costs.

Since the benefits per prevented conviction $(€ 107,211)$ do not much exceed the costs per year of detention $(360 \times € 190=€ 68,400)$, the ultimate result for society of these selective incapacitation policies is negative. Even a policy applying a low selection rate (strict selection criterion of 10 convictions) combined with a low disparity ratio (standard detention period of 2 years) still leads to a societal loss of 0.4 billion euros. The CBR based on the Ministry of Justice calculations equals 1.6:1. The final column in Table 1 gives the ratios needed to reach the break even point (Fig. 3). The extent to which these ratios are different from the 1.6:1 ratio based on the actual calculations again illustrates the inefficiency of these selective policies under the current conditions. When the outcomes of our rolling cohort method are linked to the costs of crime calculated by the Dutch Ministry of Justice, not one of the calculated selective scenarios turns out to be socially efficient.

\section{Sensitivity Analyses}

\section{Further Adjusting the Selection Criteria}

Of course the outcomes are influenced by the assumptions made in the simulations. Therefore to check for the sensitivity of our results, we preformed additional simulations altering these assumptions. In relying on a count of the total number of prior conviction across the offender's entire criminal history, the above analyses pertain to selective policies that focus on cues of persistence in offending. Selective policies relying on information on other or combinations of criminal career dimensions may yield different results. Offending frequency in the preceding period for example, may provide a selective criterion that ultimately leads to a more efficient policy. Though criminal career dimensions are known to be correlated, that is offenders who offend frequently and seriously also tend to have elongated criminal careers, whether or not the use of some other criterion produces more efficient policy, remains an empirical question. ${ }^{12}$ We therefore replicated the above analysis, but this time adding a temporal requirement to the selective criterion, namely that the number of offenses rendering offenders liable for selective treatment had to have had occurred in the 5 years directly preceding the year of conviction. Results of these additional analyses are presented in Table 2 which mirrors Table 1, but for the augmented selection criteria.

As can be noticed comparing Tables 1 and 2, selective policies augmented with the temporal requirement yield less benefits; the number of prevented convictions being lower across all scenarios. This is due to the fact that fewer offenders meet the augmented

${ }^{12}$ We thank a reviewer for addressing this issue. 


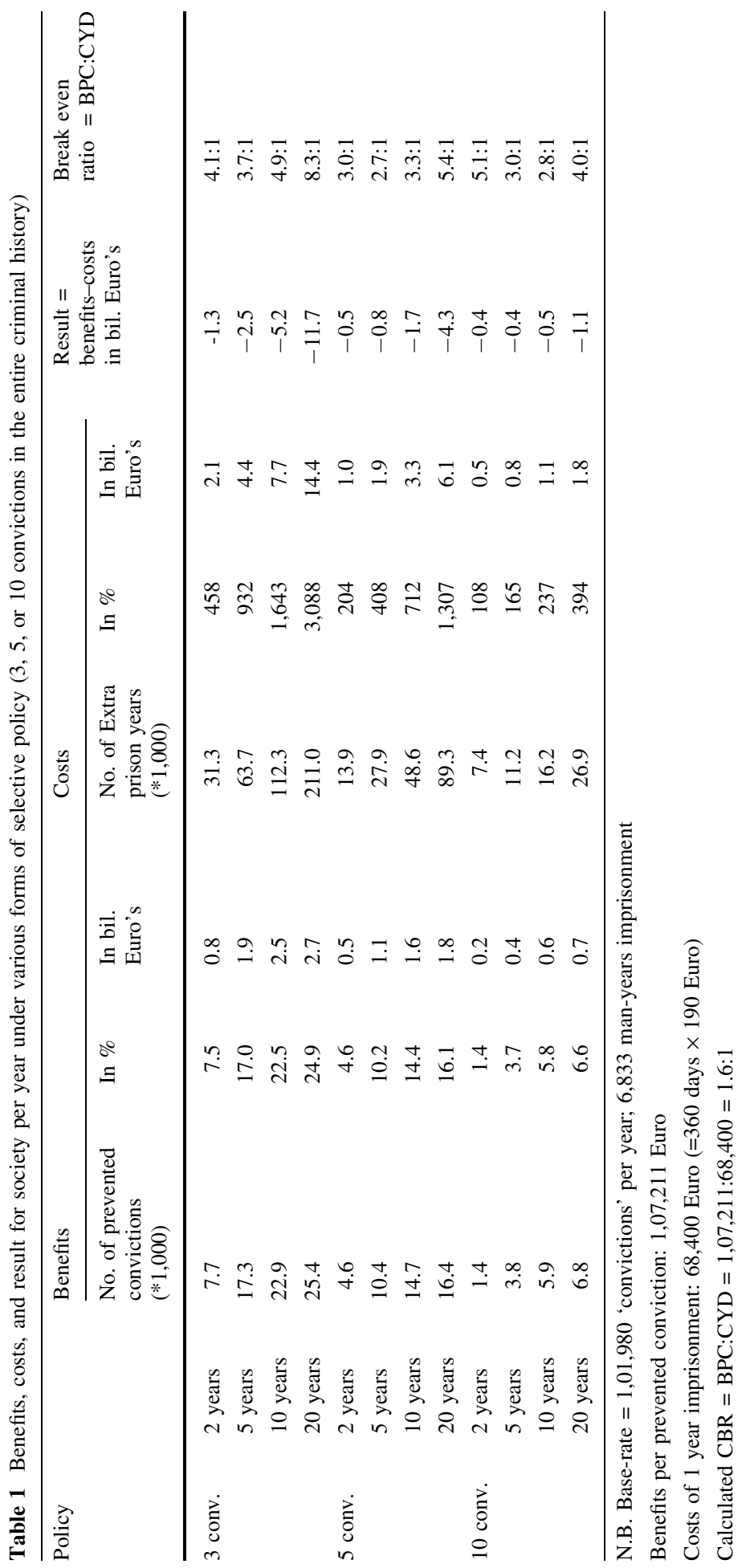


Fig. 3 Benefits and costs of a 3 strikes 5 year-selective policy under different assumptions of conviction probability disparity between frequent and occasional offenders

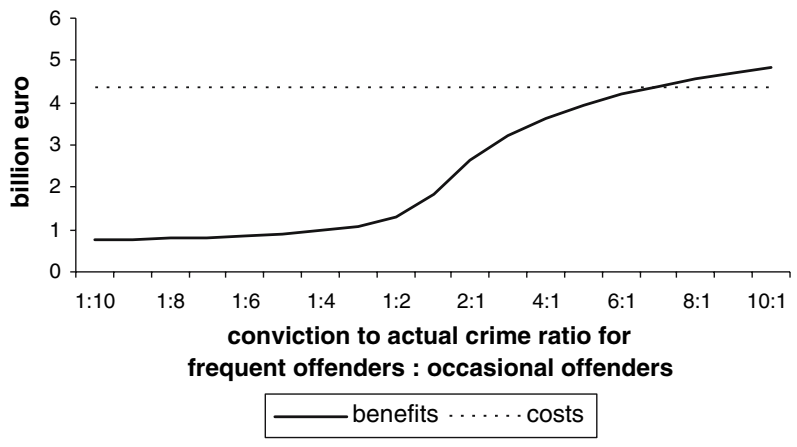

selection criteria; they did accumulate three 'strikes', but did not do so in the 5-year window. The lower benefits of the augmented selective policies are-to some extentbalanced by lower costs. Fewer offenders are imprisoned under these policies, lowering the costs of imprisonment. Yet, while less so than the scenarios pertaining to all prior convictions, the ultimate societal result for most of the augmented selective policies comes out negative.

\section{Differentiating the Probability of Conviction}

Our analyses - especially the cost benefits analyses - also make assumptions on the ratio of convictions to actual crimes. In its basic form, our use of the Ministry of Justice's calculations of the total costs of crime assumes that ratio to be equal across offenders. This however may not be the case. Frequent offenders could be argued to have a higher probability of conviction given an offense since the police may be especially alert to their actions and prosecutors may be more likely to bring cases against them. The reverse could also be true. Frequent offenders may for example become more expert in committing their crimes undetected. These and similar processes can be accounted for by adding weights to each conviction based on offender or offence characteristics which leads to more finessed benefit estimates being reached. Since it is unknown whether frequent offenders will actually have committed more crimes than occasional offenders for every conviction registered, we also estimated the benefits of each selective policy under the condition that the probability of conviction for frequent offenders was either higher or lower than that of non-frequent offenders. For this purpose we defined frequent offenders as offenders with more than five prior convictions under prevailing policy in 1977.

Results of these analyses are given in Table 3 which, for each of the selective scenarios, shows the result for society under different assumptions regarding the conviction/actual crime-ratio for frequent and occasional offenders. The first column of Table 3 gives the result for society under the assumption that the number of actual crimes behind every conviction is five times higher for non-frequent offenders than for frequent offenders. Thus, under this 1:5 assumption the probability of conviction for frequent offenders is higher. The second column gives the ultimate result for society assuming that both frequent and occasional offenders have the same probability of conviction given an actual crime (given the original analyses were based on this assumption, these results are similar to those in Table 1). The third column shows the ultimate societal result assuming the probability of conviction for frequent offenders is five times lower than that of nonfrequent offenders. The fourth column gives the 'break-even' point, the ratio for which prison costs equal the benefits in terms of averted damage from offenses prevented. This is 


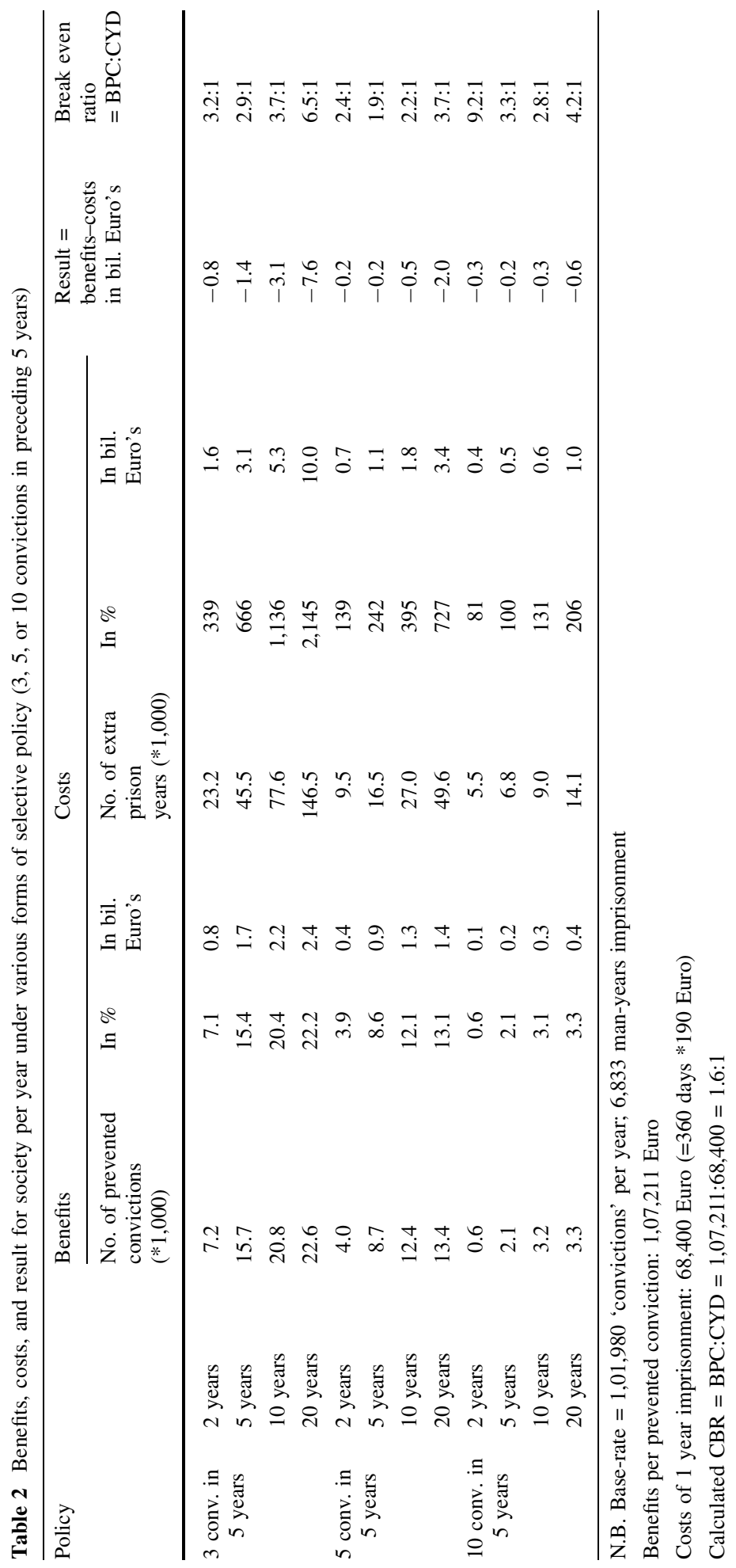




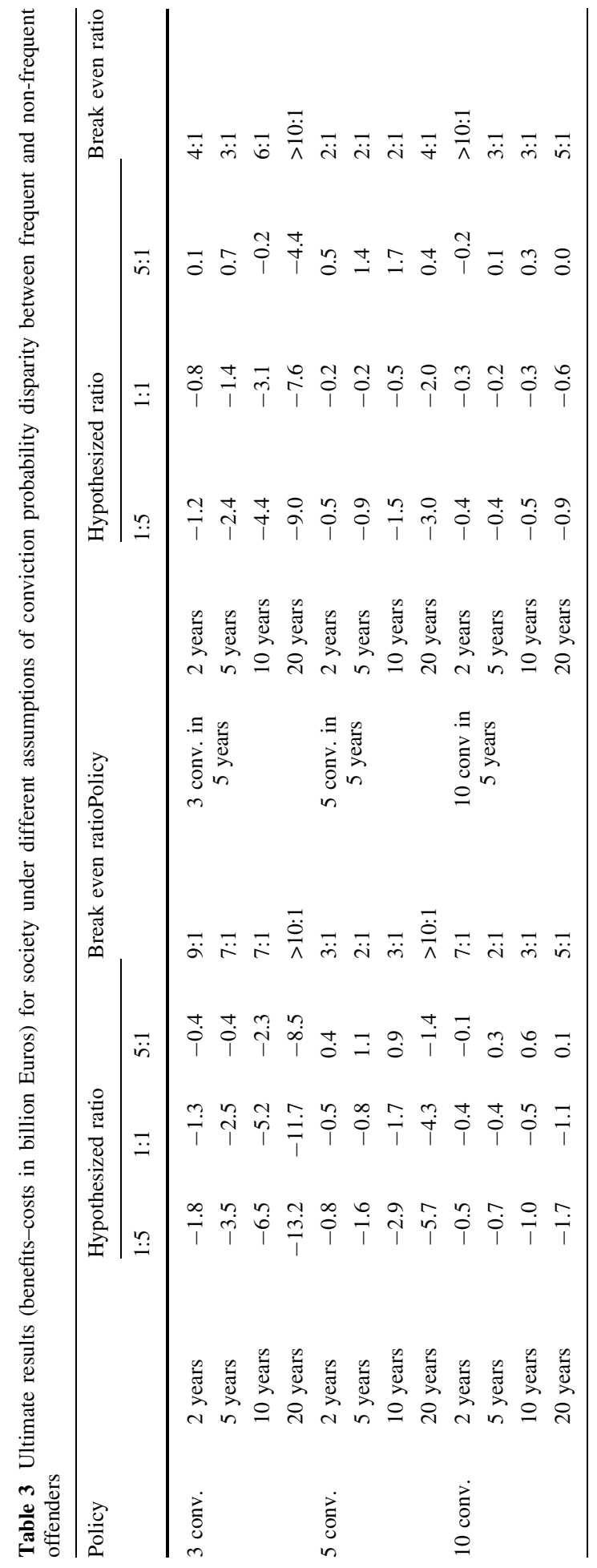


also graphically illustrated in Fig. 3 for the three strikes 5 year imprisonment-scenario: as the assumed probability of conviction for frequent offenders starts to decrease (relative to that for occasional offenders), that is the number of actual crimes behind every conviction starts to increase, benefits of actual crimes prevented starts to approach the total costs of imprisonment. Under the assumption that frequent offenders commit more than seven times as many actual crimes for each conviction than occasional offenders, the benefits of this particular scenario equal its costs. An even greater disparity between frequent and occasional offenders leads the selective scenario to become ultimately beneficial. However, in interpreting these results it must be kept in mind that the disparities mentioned are relative, that is if the actual number of crimes behind every conviction for occasional offenders is 1 , that for frequent offenders is assumed to be 7 . If however the actual number of crimes behind every conviction is 10 for occasional offenders, the 1:7 ratio means that the assumed number for frequent offenders is 70 .

The first panel in Table 3 shows the results from the selective scenarios using total criminal history as the basis of selection. For policies with a high selection rate to be efficient the number of actual crimes behind every conviction must be large relative to that of occasional offenders. However, for policies selectively sentencing offenders at five or 10 prior convictions to a period of 5 years imprisonment, the assumption that frequent offenders are half as likely to be convicted given an actual crime as are occasional offenders suffices to reach the point where benefits of prevented crimes equal prison costs.

The second panel of Table 3 reports the results for the augmented selective policies (based on the number of convictions only in the preceding 5 years). Given that for these policies the discrepancy in costs and benefits is smaller under the assumption of equal conviction probabilities for frequent and occasional offenders, less disparity in conviction probability between frequent and occasional offenders has to be assumed for these augmented policies to break even.

\section{Wastage of Prison Capacity}

Finally, we examine the efficiency of selective incapacitation policies in terms of wastage of prison capacity. The efficiency of any incapacitative policy-and especially a selective incapacitation policy where sentence enhancement is high-is also tied to the relationship between the length of imprisonment and the residual criminal career duration of those incapacitated. If incapacitation extends beyond a criminal career's termination, no incapacitation effect will be achieved beyond that point. If we shift our attention to the prospective part of the CCLS-data, that is to the sample's criminal career subsequent to 1977, we are able to estimate the accuracy of the various selective policies. To examine the wastage of prison capacity we return to the selective scenarios presented in Figs. 1 and 2 and Table 1 (in which selection is based on the total number of prior convictions). For these scenarios we estimate how many offenders would be incapacitated under a selective policy whereas in the control condition, they would accumulate no, or very few convictions. ${ }^{13}$

To answer this question, Table 4 gives the percentage of offenders-once the effects of a selective policy have stabilized-whose incapacitation does not prevent any additional convictions. Table 4 shows that, using a policy under which the frequent offender criterion is set at three convictions and the standard prison term is 2 years, $68.2 \%$ of the offenders

13 As we use data on convictions, not actual crimes, the term 'wastage' refers only to the lack of additional convictions. 
Table 4 Percentage of offenders (cumulative) inefficiently imprisoned per year of imprisonment under various forms of selective policy

\begin{tabular}{|c|c|c|c|c|}
\hline \multirow[t]{2}{*}{ Year } & \multicolumn{4}{|c|}{ Form of selective policy } \\
\hline & 3 conv. 2 years & 3 conv. 5 years & 3 conv. 10 years & 3 conv 20 years \\
\hline 1 & 68.2 & 59.7 & 50.0 & 42.0 \\
\hline 2 & 81.2 & 64.9 & 53.4 & 44.2 \\
\hline 3 & - & 70.5 & 56.9 & 46.3 \\
\hline 4 & - & 76.8 & 61.8 & 49.4 \\
\hline 5 & - & 87.5 & 66.8 & 52.6 \\
\hline 10 & - & - & 88.9 & 62.0 \\
\hline 15 & - & - & - & 76.9 \\
\hline \multirow[t]{2}{*}{20} & - & - & - & 94.9 \\
\hline & 5 conv. 2 years & 5 conv. 5 years & 5 conv. 10 years & 5 conv 20 years \\
\hline 1 & 51.0 & 34.6 & 29.6 & 23.9 \\
\hline 2 & 74.1 & 43.5 & 36.8 & 28.3 \\
\hline 3 & - & 54.3 & 39.3 & 30.8 \\
\hline 4 & - & 66.7 & 44.4 & 34.0 \\
\hline 5 & - & 77.8 & 50.8 & 38.0 \\
\hline 10 & - & - & 87.1 & 53.6 \\
\hline 15 & - & - & - & 71.3 \\
\hline \multirow[t]{2}{*}{20} & - & - & - & 94.7 \\
\hline & 10 conv. 2 years & 10 conv. 5 years & 10 conv. 10 years & 10 conv 20 years \\
\hline 1 & 70.4 & 48.9 & 41.9 & 40.8 \\
\hline 2 & 82.5 & 50.9 & 41.9 & 40.8 \\
\hline 3 & - & 53.7 & 41.9 & 40.8 \\
\hline 4 & - & 66.3 & 44.7 & 43.6 \\
\hline 5 & - & 77.3 & 52.6 & 50.0 \\
\hline 10 & - & - & 79.5 & 58.6 \\
\hline 15 & - & - & - & 72.5 \\
\hline 20 & - & - & - & 80.1 \\
\hline
\end{tabular}

who would be detained on this basis must be regarded as wastage of prison capacity: no single conviction is prevented by their detention. If three convictions are followed by a prison term of 5 years, no convictions will be prevented in that period for $59.7 \%$ of the selectively detained offenders. If we count offenders who would only be convicted once or twice as wastage of prison capacity (which surely seems appropriate for the scenarios with a long prison term), then the percentage is considerably higher. ${ }^{14}$

\footnotetext{
${ }^{14}$ The percentages in Table 4 are based on offenders who would not have been imprisoned on the basis of the offense they committed in that year under the prevailing non-selective policy, but who would have been detained under a selective policy. This avoids having offenders who would be detained for a longer period under the present policy being erroneously counted as false positives: after all, because they were imprisoned, these offenders could not obtain any more convictions. Because it cannot be ruled out that, during the total period of their selective detention, offenders would also have been detained under the non-selective policy, the number of offenses prevented may be somewhat underestimated. It should also be noted that the number of longer prison terms in our sample was very small.
} 
Wastage of prison capacity may also follow from incapacitating offenders beyond the termination of their criminal careers. The detention of offenders who would not have been given any further convictions - see Table 4-is already inefficient in the first year. Each year a percentage of prisoners is added to this that spend the year in prison, whereas under non-selective policy, they would not have been convicted again during that year. In the second year of incapacitation under a three convictions-2 year imprisonment scenario $81.2 \%$ of the prisoners would have accumulated no further convictions if they had been released. The wastage of prison years rises as the prison terms are longer. For example, if three convictions are followed by a prison term of 5 years, $64.9-87.5 \%$ are wastefully imprisoned in the second and 5th year of their sentence respectively. Under a selective approach for frequent offenders, a great many people are detained well beyond the termination of their criminal career. This leads to an inefficient utilization of the detention capacity.

A comparison of the columns in Table 4 shows that the greater the disparity ratio, the smaller the number of false positives. This is partly due to the fact that when policy is stricter, many offenders have already been put away by the selective policy. But more importantly, the period for which the number of convictions is calculated becomes longer as the prison term increases. So on balance, there are fewer offenders who stay unconvicted for the full 20 years than there are offenders who do so the first two or 5 years after their detention on the basis of the criterion.

A comparison across the rows shows that a policy scenario that works with a criterion of five convictions, gives a better result than selection after three convictions. An even stricter selection rate of 10 convictions leads again to more prison wastage. This seems primarily to be caused by an aging-out effect: the average age of offenders who meet such a strict criterion is higher (34 years compared to 28 and 29 years under a policy of three and five convictions respectively). It takes more time to build up such a criminal history. This again increases the chance that at the moment of selective detention, their criminal behavior already exhibits a downward trend.

\section{Conclusion}

Increasingly there have been calls for a targeted approach to frequent offenders in recent years and several countries-following the example of the U.S.- have implemented selective incapacitation policies. This is done even though the possible consequences of such measures are far from clear. The aim of this paper was to obtain more insight into the possible incapacitation effects of selectively imprisoning frequent offenders in the Netherlands.

The conclusions on the incapacitative effect of selective policies are clear. Selectively incapacitating presumed frequent offenders on the basis of the number of offenses they have committed in the past - or in the preceding 5 years-leads to a substantial decline in crime. This decline is the greatest in the first years after the introduction of the selective policy as a rising share of offenders are selectively imprisoned. After some time, depending on the duration of the standard prison term, some of the offenders having completed their prison term rejoin the population, thus causing crime to rise again. The ultimate result of our simulations-assuming only incapacitatative effects-is a $25 \%$ decrease in crime under the strictest regime. However, these benefits are offset by the fact that the introduction of a selective policy causes the prison population to rise considerably; 
up to 45 times the population under prevailing non-selective policy for a very strict selective regime. As a result, if a selective policy based on the total number of prior convictions is to be efficient, the average conviction prevented by the selective incapacitation of frequent offenders would have to generate four to eight times as much in benefits than it would cost detaining an offender for 1 year.

On the basis of the total crime costs for 2004, however, the benefits from preventing an average conviction are only approximately twice as high as the costs of 1 year of prison. Under the assumption of equal probability of conviction across all offenders this would mean that even the selective incapacitation scenario with the most favorable CBR (five prior convictions in the entire criminal history, 5 years of prison) is only efficient if the costs per prisoner can be reduced from 190 to 58 euros per day, which cannot be considered a realistic option. Allowing disparity in the probability of conviction however, may-at current prison costs - result in a break even situation for some selective policies if frequent offenders are less than half as likely as non-frequent offenders to be convicted given an actual crime.

Finally, risk estimation merely on the basis of criminal past generates high wastage of prison capacity. A lower selection rate (employing a stricter selection criterion) reduces this problem, but the resulting policy has hardly any added crime reduction value over prevailing non-selective policy.

In conclusion, a few further comments should be made. First, our analyses focus only on the incapacitative effect of selective policies and do not take into account general or specific deterrent effects. If these effects are large, selective policies may prove much more beneficial. However, our simulation did not include the possible criminogenic influence of imprisonment either. The prime objective of a selective detention policy is the safety of society; resocialization of offenders has low priority. Developmental criminological research raises serious doubts about the continuity in offense behavior which is at the heart of selective policy. The behavior of frequent offender is not free from external influences, and these influences may inhibit crime, but they may also increase the chances of a subsequent offense. The CCLS has already shown that previous criminal behavior increases the probability of criminal behavior later in life; to what extent detention has an effect is a matter currently under investigation (Nieuwbeerta et al. 2004). If imprisonment does turn out to have a criminogenic effect, this may cancel out the effect of a selective policy in full or in part, because under a selective policy offenders are detained who would not have been sentenced to a prison term under a non-selective policy. In that case, only a selective policy that entails a very long prison term would lead to a decline in crime (which raises the question of how many penal institutions we would need to build to accommodate all these prisoners).

Second, the current focus on incapacitative effects may explain some of the differences in elasticity - the percentage of crime reduction given a $1 \%$ increase of the prison population-compared with earlier macro-level studies. Our simulation filtered out any behavioral or system effects that may have affected earlier results. For example, benefits from U.S. Three Strikes laws have fallen below expectation, at least partly due to judges balking at sentencing offenders under these new policies (Clark et al. 1997).

Additionally, differences between the U.S. and the Netherlands in crime and prison rates as well as in the fraction of convicted offenders sentenced to prison and the average sentence length served under non-selective policy, may have account for our results. A recent report by the Bureau of Justice Statistics (Farrington et al. 2004) comparing trends in crime rates and severity of punishment across the U.S., the Netherlands and several other European countries showed for instance that in 1981 the burglary rate in the US to be more than double that of the Netherlands while the incarceration rate (for burglary) was about 
1.3 times as high. Percent of convicted offenders sentenced to prison were $54 \%$ for the U.S. and $90 \%$ for the Netherlands, the average sentence length in the U.S. was 37 months compared to 13 months in the Netherlands-17 versus 11 months when measuring only time actually served. Similar patterns were found for other types of offences. In general, the absolute number of prisoners in the Netherlands being low compared to the U.S. means that a relative increase in the Dutch prison population involves fewer prisoners in terms of absolute numbers. Furthermore, the impact of selective policies is mediated by the fraction of convictees that were already sent to prison under non-selective policy. While this fraction appears to be somewhat higher in the Netherlands, ${ }^{15}$ this is offset by the relatively lenient sentencing policy in the Netherlands. ${ }^{16}$ In our data the average prison term under prevailing Dutch non-selective policy averages below 100 days for those actually sentenced to prison in 1977. Even a mandatory prison term of 2 years thus leads to great sanction disparity (i.e. a sevenfold increase in sentence length) among frequent offenders under the selective versus the non-selective scenario, which in turn explains the steep rise in prison costs under selective scenarios. Our results are comparable to those of Andersson (1993) who, conducting simulations on Swedish birth-cohort data, found that a mandatory prison term of 2 years following every second conviction led the prison population to increase with a fivefold.

A final remark in respect of the analyses is to what extent data from 1977 can be generalized to draw conclusions about our present day and age. The primary object of the Criminal Career and Life Course Study is to chart the way criminal behavior develops in the course of a person's life. To do this properly, a long follow-up period is required, which is why we opted for a cohort from 1977. The rolling cohorts method used here makes the assumption that the composition of the successive cohorts remains the same. This is most likely not the case in practice. For instance, only a very small number of offenders were regarded as drug addicts in 1977, and the social composition of the group of offenders was different than it is today. On the other hand, a recent report by the Dutch Ministry of Justice on recidivism in the 1997 to 2003 conviction cohorts (Wartna and Tollenaar 2006) shows these cohorts to be highly comparable to the 1977-cohort used here, both in criminal histories and recidivism rates, suggesting the distribution of offending may not differ very much over time. Still, we recommend that the analyses reported here be replicated in relation to the expected decrease in registered crime and the expected growth in the prison population using data from a more recent cohort. However, to determine the proportion of false positives, prospective recidivist data covering a longer period-and thus from an older cohort-are indispensable. ${ }^{17}$

\footnotetext{
${ }^{15}$ Note however that the BJS-report mentions the percentage of offenders found guilty by a judge who were incarcerated. In the current study 'convictions' were defined as both guilty verdicts and policy waivers. In so far the Dutch public prosecutor is more likely to waive criminal cases for policy reasons, the percentage of 'convicted' offenders may come closer or even drop below that of the U.S.

${ }^{16}$ While burglary rates in the U.S. have increasingly become similar to those in the Netherlands, the difference in sentence length remains.

${ }^{17}$ It must be remarked that the analyses do not connect seamlessly to present Dutch practice. The ISD defines the repeat offender as an offender with three convictions, but sets the further condition that this must have happened in the past 5 years. The latter is to avoid the selective detention, on the basis of this act, of offenders with a long criminal career behind them, but a low frequency of offenses. No such condition was set for our analyses, nor was it by the American three-strikes legislation; this might have a negative effect on the efficiency calculated of the various penal scenarios. Analyses of the conviction density, the number of convictions per year, do actually show a strong correlation between conviction density and length of the criminal career for the group of people studied here. In this respect, the outcomes of the scenario studies conducted for this paper will therefore not differ much from the practical outcomes of present policy.
} 
Lastly, we would like to reflect on the implications of our research results. Selectively incapacitating offenders on the basis of an estimation of their future behavior rooted in their past criminal behavior points to the growing influence of risk-oriented thinking in criminal legislation and judicial policy (Feely and Simon 1992). Frequent offenders belong to the category of offenders with a high risk of recidivism, and society thinks that they therefore ought to be removed from its midst. Offenders with a sufficiently extensive criminal history are thus penalized not for what they have done, but for what they are expected to do in the future. This implies that a prison term is converted from a punitive into a preventive measure, one that our results suggest is used unnecessarily in many cases. Moreover, under a selective policy, there is no longer any relationship between the offense committed and the duration of the sentence. Selective incapacitation conflicts with a number of fundamental principles of the Dutch criminal law system. On the basis of our research results, which were mainly negative about the selective detention of frequent offenders, one may well wonder whether such a fundamental change to the Dutch criminal law system is actually opportune, and even whether this policy has any empirical legitimacy. It is possible and even likely that criminological research would point to other policy alternatives, primarily those that do find support in criminological research (Donohue III and Siegelman 1998), as a more obvious choice-for example, investing more in the socioeconomic functioning of prisoners by improving and expanding the probation and aftercare service.

Acknowledgments We would like to thank the editors of the special issue and three anonymous reviewers for their constructive comments on earlier drafts of this paper.

\section{References}

Andersson J (1993) A longitudinal simulation study of incapacitation effects (Project Metropolitan no. 35). Department of Sociology, University of Stockholm, Stockholm

Austin J, Irwin J (2001) It's about time: America's imprisonment binge. Wadsworth, Belmont, CA

Avi-Itzhak B, Shinnar R (1973) Quantitative models in crime control. J Crim Justice 1:185-217

Barnett A, Lofaso AJ (1985) Selective incapacitation and the Philadelphia cohort data. J Quant Crimin $1(1): 3-36$

Bernard TJ, Ritti RR (1991) The Philadelphia birth cohort and selective incapacitation. J Res Crime Delinq 28(1):33-54

Block CR, Werff Cvd (1991) Initiation and continuation of a criminal career: who are the most active and dangerous offenders in the Netherlands (105). WODC, Ministerie van Justitie, Den Haag

Blokland AAJ (2005) Crime over the lifespan; trajectories of criminal behavior in Dutch offenders. NSCR, Leiden

Blokland AAJ, Nagin DS, Nieuwbeerta P (2005) Life span offending trajectories of a Dutch conviction cohort. Criminology 43(4):919-954

Blokland AAJ, Nieuwbeerta P (2005) The effects of life circumstances on longitudinal trajectories of offending. Criminology 43(4):1203-1240

Blumstein A (2005) An over view of the symposium and some next steps. Ann Am Acad Pol Soc Sci 602:242-258

Blumstein A, Cohen J, Nagin DS (eds) (1978) Deterrence and incapacitation: estimating the effects of criminal sanctions on crime rates. National academy of Sciences, Washington, DC

Blumstein A, Cohen J, Farrington DP (1988) Criminal career research: its value for criminology. Criminology 26(1):1-35

Blumstein A, Canela-Cacho JA, Cohen J (1993) Filtered sampling from populations with heterogeneous event frequencies. Manage Sci 39:886-899

Canela-Cacho JA, Blumstein A, Chohen J (1997) Relationship between the offending frequency $(\lambda)$ of imprisoned and free offenders. Criminology 35(1):133-175 
Clark J, Austin J, Henry DA (1997) “Three strikes and you're out": a review of state legislation. National Institute of Justice, Washington, DC

Cohen J (1978) The incapacitative effect of imprisonment: a critical review of the literature. In: Blumstein A, Cohen J, Nagin D (eds) Deterrence and incapacitation: estimating the effects of criminal sanctions on crime rates. National academy of Sciences, Washington, DC

Cohen MA (2005) The costs of crime and justice. Routledge, London

Cohen MA, Miller TR (2003) Willingness to award. Nonmonetary damages and the implied value of life from jury awards. Int Rev Law Econ 23(2):165-181

Cushman RC (1996) Effects on a local criminal justice system. In: Sechrest DK (ed) Three strikes and you're out: vengenace as a public policy. Sage, Thousand Oaks, CA

DiIulio JJ, Piehl AM (1991) Does prison pay? The stormy national debate over the cost-effectiveness of imprisonment. Brook Rev, 28-35

Donohue JJ III, Siegelman P (1998) Allocating resources among prisons and social programs in the battle against crime. J Legal Stud 27:1-43

Farrington DP, Langan PA, Tonry M (2004) Cross-national studies in crime and justice. http:// www.ojp.usdoj.gov/bjs/pub/pdf/cnscj.pdf

Feely MM, Simon J (1992) The new penology: notes on emerging strategy of corrections and its implications. Criminology 30:449-474

Flanagan TJ, Marquart JW, Adams KG (1998) Incarcerating criminals: prisons and ails in social and organizational context. Oxford, New York

Gibbons S (2004) The cost of urban property crime. Econ J 114:441-463

Grapendaal M, Tilburg Wv (2002) Veelplegers in Netherland. Tijdschrift voor Criminologie 44(3):214-230

Greenwood PW, Abrahamse AF (1982) Selective incapacitation. RAND, Santa Monica, CA

Kempf-Leonard K, Tracy PE, Howell JC (2001) Serious, violent and chronic juvenile offenders: the relationship of delinquency career type to adult criminality. Justice Q 18:449-478

King RS, Mauer M (2001) Aging behind bars: three strikes seven years later. The Sentencing Project, Washington, DC

Kommer MM (1994) Het Nederlandse strafklimaat in internationaal perspectief. In: Moerings M (ed) Hoe Punitief is Nederland? Gouda-Quint, Arnhem

Kovandzic TV (2001) The impact of Florida's habitual offender law on crime. Criminology 39(1):179-203

Kovandzic TV, Sloan JJ III, Vieraitis LM (2002) Unintended consequences of politically popular sentencing policy: the homicide promoting effects of 'Three strikes' in U.S. cities (1980-1999). Criminol Public Policy 1(3):399-424

Levitt SD (1996) The effect of prison population size on crime rates: evidence from prison overcrowding litigation. Q J Econ 111:319-351

Marvell TB, Moody CE (2001) The lethal effects of three-strikes laws. J Legal Stud XXX(January):89-106

Mathiesen T (1998) Selective incapacitation revisited. Law Hum behav 22(4):455-476

Miles T, Ludwig J (2007) The silence of the lambdas: deterring incapacitation research. J Quant Criminol, this issue

Miller TR, Cohen MA, Rossman SB (1993) Victim costs of crime and resulting injuries. Health Aff 12(4):186-197

Moffitt TE (1993) Adolescence-limited and life-course-persistent antisocial behavior: a developmental taxonomy. Psychol Rev 100(4):674-701

Moffitt TE (2006) A review of research on the taxonomy of life-course persistent versus adolescence-limited antisocial behavior. In: Cullen FT, Wright JP, Blevins KR (eds) Taking stock: the of criminological theory, vol 15. Transaction Publishers, New Brunswick, pp 277-311

Molenaar DEG (2005) Uitgaven aan criminaliteit. In: Heide Wvd (ed) Criminaliteit en Rechtshandhaving 2004. WODC, Den Haag, pp 211-243

Moore MH (1986) Purblind justice: normative issues in the use of predictive or discriminating tests in the criminal justice system. In: Blumstein A, Cohen J, Roth JA, Visher CA (eds) Criminal careers and 'career criminals', vol 2. National academy Press, Washington, DC, pp 314-335

Nieuwbeerta P, Blokland AAJ (2003) Criminal careers of adult Dutch offenders. Codebook and documentation. NSCR, Leiden

Nieuwbeerta P, Blokland AAJ, Wittebrood K (2004) Eens crimineel, altijd crimineel? Een toetsing van 'kinds of people' en 'kinds of context' verklaringen voor de ontwikkeling van criminele carrieres. Tijdschrift voor Criminologie 46(3):210-232

Patch PC (1998) The three strikes law and control of crime in California. ACJS Today 17:1-4

Piehl AM, DiIulio JJ (1995) Does prison pay? Revisited: returning to the crime scene. Brook Rev 20-25

Piper ES (1985) Violent recidivism and chronicity in the 1958 Philadeliphia cohort. J Quant Criminol 1(4):319-344 
Piquero AR (2000a) Assessing the relationships between gender, chronicity, seriousness, and offense skewness in criminal offending. J Crim Justice 28:103-115

Piquero AR (2000b) Frequency, specialization, and violence in offending careers. J Res Crime Delinq 37(4):392-418

Piquero AR, Blumstein A (2007) Does incapacitation reduce crime. J Quant Criminol, this issue

Rajkumar AS, French MT (1997) Drug abuse, crime costs, and the economic benefits of treatment. J Quant Criminol 13(3):291-323

Shafer JR (1999) The deterrent effects of three-strikes law. FBI Law Enforce Bull 68:6-10

Shepherd JM (2002) Fear of the first strike: the full deterrent effect of California's two- and three-strikes legislation. J Legal Stud XXXI(January):159-201

Shichor D, Sechrest DK (1996) Three strikes as public policy: future implications. In: Sechrest DK (ed) Three strikes and you're out: vengenace as a public policy. Sage, Thousand Oaks, CA

Smit PR (2001) Nederland in internationaal perspectief. In: Huls FWM, Schreuders MM, Ter Horst-Van Breukelen MH, van Tulder FP (eds) Criminaliteit en Rechtshandhaving 2000. WODC, Den Haaf

Spelman W (1994) Criminal incapacitation. Plenum Press, New York

Spelman W (2000a) What recent studies do (and don't) tell us about imprisonment and crime. Crime Justice 27:419-494

Spelman W (2000b) The limited importance of prison expansion. In: Blumstein A, Wallman J (eds) The crime drop in America. Cambridge university Press, Cambridge

Spelman W (2005) Jobs or jails? The crime drop in Texas. J Policy Anal Manage 24(1):133-165

Stemen D (2007) Reconsidering incarceration: new directions for reducing crime. Vera Institute of Justice, New York

Tracy PE, Wolfgang ME, Figlio RM (1990) Delinquency careers in two birth cohorts. Plenum Press, New York

Versteegh P, Janssen J, Bernasco W (2003) Beginners, doorstromers en veelplegers - carrière criminaliteit in de politieregio Haaglanden. Tijdschrift voor Criminologie 45(2):127-139

Vitiello M (1997) Three strikes: can we return to rationality? J Crim Law Criminol 87:395-481

Walker S (2001) Sense and nonesense about crime and drugs: a policy guide. Wadsworth, Belmont, CA

Wartna BSJ, Tollenaar N (2006) Recidive 1997-2003. Ontwikkelingen in het niveau van de strafrechtelijke recidive van jeugdige en volwassen daders. WODC, Den Haag

Wittebrood K (2006) Slachtoffers van Criminaliteit. SCP, Den Haag

Wolfgang M, Figlio R, Sellin T (1972) Delinquency in a birth cohort. University of Chicago Press, Chicago

Zimring FE, Hawkins G (1995) Incapacitation: penal confinement and the restraint of crime. Oxford University Press, New York

Zimring FE, Hawkins G, Kamin S (2001) Punishment and democray: three strikes and you're out in California. Oxford University Press, New York 